\title{
The Future of Australian \& New Zealand Security Standard AS/NZS 4444?
}

\author{
$\S D r$ Matthew Warren and §§Dr Bill Hutchinson
}

§School of Computing \& Mathematics, Deakin University, Geelong, Victoria, Australia.

§School of Management Information Systems, Edith Cowan University, Churchlands, WesternAustralia, Australia.

Keywords: $\quad$ Australia and New Zealand Standard 4444, Baseline Security, British Standard 7799.

Abstract: $\quad$ Computer security is now recognised as an important consideration in modern business, with a variety of guidelines and standards currently available to enable different business environments to be properly protected. However, financial and operational constraints often exist which influence the practicality of these recommendations. New methods such as Australian and New Zealand Standard (AS/NZS) 4444 and British Standard (BS) 7799 represent standards which organisations can use to improve their security. The British have developed a certification process, which allows organisations to be certified against the BS7799 security standard. The aim of the paper is to look at the future development of AS/NZS 4444 and the associated certification scheme. 


\section{INTRODUCTION}

During the last few decades the use of Information Technology has become more widespread in all areas of society, and the types of activities that it performs or supports, have become increasingly more important. As a result, information systems are now heavily utilised by all organisations and relied upon to the extent that it would be impossible to manage without them.

The aim of risk analysis is to eliminate or reduce risks and vulnerabilities that affect the overall operation of organisational computer systems. Risk analysis not only looks at hardware and software, but also covers other areas such as physical security, human security, and business and disaster protection. In practice, there are major problems with the use of risk analysis; the time taken to carry out a review, the cost of hiring consultants and/or training staff. To overcome these negative aspects, baseline security standards were developed. Baseline security standards offer an alternative to conventional risk methods as they represent the minimally acceptable security countermeasures that an organisation should have implemented. These countermeasures are applied in a generic manner, e.g. every organisation should have the same baseline security countermeasures.

The advantages of using baseline methods include [1]:

- cheap to use;

- simple to use;

- no training is required to use the method;

- it is quicker then undertaking a full security review.

The disadvantages of using baseline methods include [1]:

- the generic nature of baseline security methods mean they may not solve all of the organisational security requirements;

- the fact that they have been designed for use within a general environment mean that they may not be suited for all environments, i.e. healthcare or small businesses;

- they do not suggest how the security countermeasures may be implemented;

- they do not contain cost benefit details.

One of the first baseline methods developed was the British standard BS7799 [2], with an associated certification scheme. This paper will look at 
the BS7799 standard and the new certification process and how it will impact upon the Australian method AS/NZS 4444.

\section{BS7799 DEVELOPMENT}

The BS7799 was originally developed as the Code of Practice for Information Security Management by the British government department of Trade and Industry [3]. In 1995 the code was accepted as British Standard 7799 and as such has become a de facto standard within Britain and Europe. BS7799 provides over 100 security guidelines structured under 10 sections to enable individuals to identify the security controls, which are appropriate to their particular business or specific area of responsibility, as shown by the sections of BS7799, which are:

1. Security Policy;

2. Security Organisation;

3. Assets Classification and Control;

4. Physical and Environmental Security;

5. Computer and Network Management;

6. System Access Control;

7. System Development and Maintenance;

8. Business Continuity Planning;

9. Compliance.

Furthermore, it identifies 10 essential basic countermeasures, which are considered to be essential in providing effective information security. These 10 basic countermeasures are intended as the minimal level of security that an organisation should implement. As well as detailing essential basic countermeasures, BS7799 also provides guidance on security policies, staff security awareness, business continuity planning, and legal requirements.

\section{BS7799 CERTIFICATION}

A newer version of BS7799 was released called BS7799-2 [4], this included the framework for BS7799 certification. The following represents the steps used for BS7799 certification [5]. The steps are:

- To establish and maintain a documented information security management system (ISMS). This should address the assets to be 
protected, the organisation's approach to risk management, the control objectives and the degree of protection required;

- To establish a management framework that includes an information security policy, an information security infrastructure, personnel security and security reviews of IT systems;

- To define the scope of the information security management system. The boundaries shall be determined in terms of organisation, location assets and technology;

- To carry out a risk assessment. This will identify the threats to the assets, vulnerabilities and impacts on the organisation and determine the degree of risk. The organisation should identify the areas of risk to be managed - based on the organisation's approach to risk management and the degree of assurance required - and determine the options for the sets of controls to manage the risk;

- To select the control objectives and controls that need to be implemented. This selection will need to be justified. If necessary, additional controls outside BS7799 may be selected;

- To prepare a 'statement of applicability'. This should include details of the selected control objectives and the reasons for their selection. In addition, the reasons for non-selection of controls must be included in this statement.

\subsection{Structure of BS7799 Certification}

In 1995 a BS7799 certification feasibility project was started [6] and the resulting scheme was launched in April 1998 (see Figure 1). The Scheme is owned by the British Standards Institute, on behalf of the British Department of Trade and Industry (DTI). They will decide what can and cannot be done. In order to be awarded a certificate, an organisations' ISMS will be audited by a BS7799 assessor. The assessor cannot also be a security consultant because of their commercial bias. The assessor will work for a certification body (such as BSI "Assessment Services Limited" and Lloyd's "Register Quality Assurance Limited").

The certification body will award the certificate. The certificate will document the scope of the organisations' ISMS and other relevant details, such as the statement of applicability. Only certification bodies that have been duly accredited by the UK accreditation service (UKAS) will be able to issue certificates. 


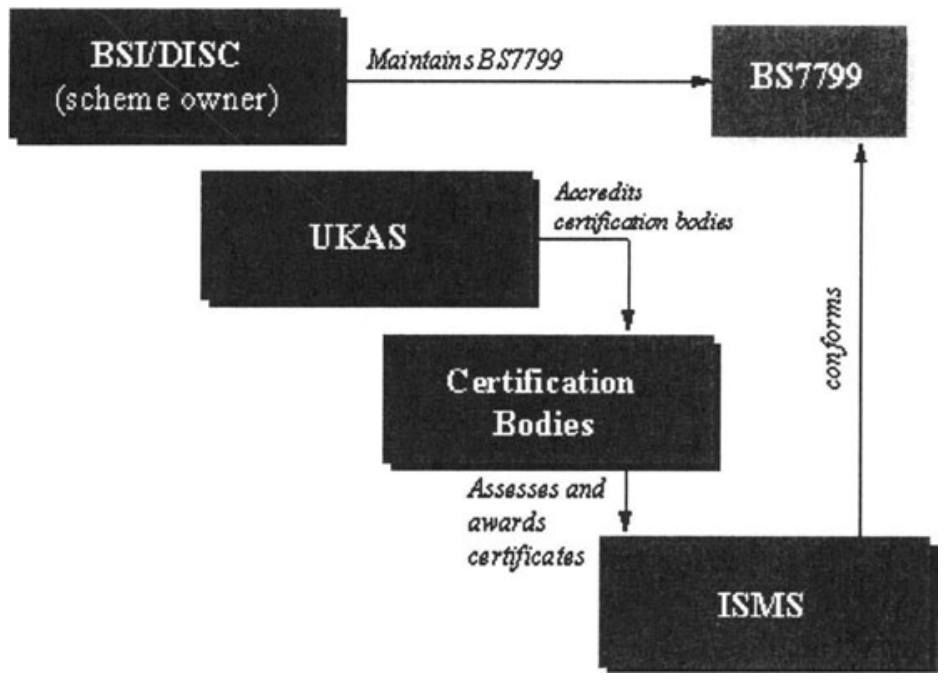

Figure 1. Bodies involved with UK BS7799 Certification

\section{ADVANTAGE AND DISADVANTAGES OF BS7799 CERTIFICATION}

There are many advantages and disadvantages for an organisation to be certified against BS7799, these include:

- They provide a common framework for organisations to develop, implement and measure their information security management;

- They allow businesses to become certified against a common security framework. This will allow an organisation to measure their existing security against the framework; helping to promote intercompany trading since appropriate quality security management methods can be assumed;

- They raise security awareness within an organisation;

- They allow organisations to quickly implement security best practice methods, even if they have had no prior experience;

- They reassure customers that the organisational security has been externally reviewed and resulted in certification.

But with any certification scheme there are problems, in terms of the BS7799 these problems are: 
- Due to the high level nature of the standards, some without an IT background may find it hard to understand the guidelines;

- There might be high costs associated with implementing the required components of the standard;

- Organisations may have to implement guidelines which they feel are not needed in order to comply with the certification process;

- How easier can small organisations comply with the certification scheme?;

- Once an organisation becomes certified they may become complacent;

- Organisations are only certifying themselves against a baseline standard, i.e. a minimal level of security.

\section{AS/NZS 4444 DEVELOPMENT}

The Australian and New Zealand standard committees in response to BS7799 and industries requirements, developed a set of security standards entitled AS/NZS 4444 - Information Security Management [7]. It was based upon the principles of BS7799-2 and recommended minimal security countermeasures that an organisation should implement to help improve security. The guidelines were grouped in the same sections as the originally BS7799 standards.

Some of the guidelines were altered to take into account the different operational circumstances, e.g. replacing references to the British Data Protection Act with references to Australia's and New Zealand's Information Privacy Principles.

The Australian and New Zealand approach represents security guidelines that can be adhered to and not certified against, this represents a less formal approach to security management. This approach is better suited to industry where there is a mixture of organisational types where varying computing resources exists. This means that organisations are able to pick the guidelines most appropriate to them.

In the evolving electronic world (e.g. electronic commerce) there is a rapidly growing requirement for assurance to management, business partners and customers, that appropriate measures are used to provide adequate security management of their information environments [8]. 


\section{AS/NZS 4444 CERTIFICATION}

There is a desire from the Australian and New Zealand business community to develop a national certification process. This would require the formation of a certification framework involving the relevant bodies and then the practical details relating to the actual certification would have to be determined. Organisations would then have to be formally certified. The biggest problem is the effort required to develop a new certification process and framework. Another problem is the limited international impact that a joint Australia and New Zealand certification scheme would have.

Perhaps a better approach is to adopt an existing baseline standard and certification scheme which is widely used throughout the world. The ideal candidate would be BS7799. The BS7799 standard and certification process is widely used throughout Europe and Asia. By adopting this method as a national standard, organisations will be able to be certified against a national and international security standard. This approach has been now adopted by Australian and New Zealand as a way forward for AS/NZS 4444. This new version of AS/NZS 4444.1 [9] has been publicly released for general comments, the next stage will then be the final acceptance of the new version. This means that BS7799 would have been nationally adopted by Australia, Britain, New Zealand and The Netherlands.

The biggest problem facing Australia and New Zealand is developing a new certification process for AS/NZS 4444. The reason for this is that it is being developed afresh, and as such needs considerable time and effort to be spent. It is impossible to adopt the British Certification scheme shown by figure 1, because those institutions may not exist within Australia and New Zealand. But it is important to develop a certification scheme that is closely to the BS7799 certification scheme currently operating in the UK and the Netherlands, with the intention of establishing mutual recognition between the schemes [10].

\section{THE NEXT STEP FOR AUSTRALIA AND NEW ZEALAND}

One of the biggest areas of concern has been that Australia and New Zealand were adopting a security method of another country (UK) and what would happen if sections were added that were not relevant to Australia and New Zealand. For example, what will happen when the European Data Protection directive [11] becomes a European law and thus a UK law? The 
next version of BS7799 would include new references to that law and could include guidelines for restricting data transfer to unsecured countries. The latest method of BS7799 [12] has overcome many of these fears by adopting a much more generic approach to complying with national legislation.

Perhaps the another key issue is what will certification offer Australia and New Zealand. Recent research [13] has shown that in Australia $\$ 100$ million is currently being lost to fraud (including computer-based fraud) per year. If certification can reduce this figure then this is the way forward for Australia and New Zealand. However within Britain, where they do have the certification process, research [14] suggests that only $19 \%$ of British Companies comply with the standard. Another survey within Britain has shown that only $3 \%$ of organisations surveyed were in a position to be certified against BS7799 [15]. So has certification helped Britain? Perhaps not.

\section{CONCLUSION}

The BS7799 standard is a first step towards internationally recognised baseline security standards, against which organisations can certify themselves. Any improvement of an organisation's computer security can only be a good thing, but will certification be the answer?

The Australian and New Zealand method AS/NZS4444 is at a new beginning. Instead of just developing a national security standard it is helping to form an international security standard.

Therefore in conclusion, it is better for Australia and New Zealand to adopt the BS7799 standard and similar certification scheme rather than developing a local scheme with would have a minor international impact. Perhaps also of concern is the fact that much attention has been placed upon developing security baselines, which only represent a minimal level of protection. But for many organisations even adopting a minimal security standard reflects a big step forward.

\section{REFERENCES}

1. Warren M.J, A new hybrid approach for Risk Analysis, IFIP WG11.1 - Information Security Management Conference, Copenhagen, Denmark, (1997), 123 - 130. 
2. British Standards Institute, BS7799 - Code of Practice for Information Security Management, UK, (1995).

3. Department of Trade and Industry, Code of Practice for Information Security Management, UK, (1993).

4. British Standards Institute, BS7799-2, Information security management, Specification for Information Security Management Systems, UK, (1998).

5. Department of Trade and Industry, Accredited Certification against BS7799: A Code of Practice for Information Security Management, UK, (1997).

6. Department of Trade and Industry, Plan for a BS7799 Certification Service: Project Summary, UK, (1997).

7. Australian and New Zealand Standard Committee, AS/NZS 4444:1996 Information Security Management, Australia, (1996).

8. Business Case: Certification/Accreditation Service for AS/NZS 4444, Standards Australia Committee: IT/12/4, Australia, (1998).

9. Australian and New Zealand Standard Committee, AS/NZS 4444.1 Information Security Management, Australia, (1998).

10. Information Security Management-Certification Scheme, Standards Australia Magazine, No 2/99, Australia (1999).

11. European Data Protection directive, European Union, (1995). (http://www2.echo.lu/legal/en/dataprot/directiv/directiv.html)

12. British Standards Institute, BS7799-1:1999 - Information Security Management, UK, (1999).

13. 1997 - Fraud Survey, KPMG, Australia, (1997).

14. Audit Commission, Audit Commission Update - Ghost in the machine, UK, (1998).

15. British Standards Institute, Results of the C:Cure Survey-1999, (UK), (1999). 